\title{
Estimation of Extreme Flows in Nkana River to Verify the Adequacy of Naming'ongo Bridge Waterway
}

\author{
Zacharia Katambara*, Joseph J. Msambichaka, Joseph Mkisi \\ Department of Civil Engineering, Mbeya Institute of Science and Technology, Mbeya, Tanzania \\ Email: "zacharia.katambara@mist.ac.za, ${ }^{*}$ zkatambara1@gmail.com
}

Received December 26, 2012; revised January 26, 2013; accepted February 5, 2013

\begin{abstract}
The response by the government of Tanzania to food security and poverty alleviation in the Naming'ongo area in Mbozi District has been to develop Naming'ongo irrigation scheme as well as construct a bridge across River Nkana to connect the farms and other parts of the district to facilitate a reliable transportation of the produce to the market. The Australian Water Balance Model was calibrated by using 10 years data from a nearby sub-catchment of Mbarali. The Naming'ongo Sub-catchment was delineated form a $30 \mathrm{~m}$ digital elevation model. The observed rainfall was obtained from Mbozi Meteorological station. The study approximated the peak flows in River Nkana for a return period of 50 years to be slight above $560 \mathrm{~m}^{3} / \mathrm{s}$. This was considered to be adequate for the proposed structure. The study recommends that when undertaking human activities such as deforestation and cultivation an account for soil and environmental conservation should be considered. While it is necessary to establish a monitoring system within the catchment, the designs of future hydraulic structures should incorporate stream flow measuring facilities.
\end{abstract}

Keywords: Extreme Flow; Australian Water Balance Model; Stream Flow Simulations; Catchment Delineation; Parameter Estimation

\section{Introduction}

The scale of hydrological monitoring in many catchments is inadequate and the trend suggests that this will even decrease due to various reasons. In Tanzania, just like many other developing countries, there is insufficient financial support from the respective government as well as the development partners that would be critical in enabling the establishment of new or repair of all the faulty monitoring stations, lack of committed gauge readers and the accompanying supervision of the data collection and verification processes, major change in economic perspective that witnessed increase of unemployment rate [1]. On the other hand, the demand for food to feed the growing population is increasing and $80 \%$ of the food producers are subsistence farmers located in rural areas. The majority of these farmers practice rain fed agriculture making them vulnerable to insufficient rainfall and longer dry spells that result to food insecurity. It is against this background that the Tanzanian government has undertaken initiatives aimed at improving food security by the establishment of several irrigation infrastructures and their associated services across the country as a response. One such initiative is the Naming'ongo Bridge and Irrigation Scheme located

*Corresponding author. in Mbeya Region, Tanzania (Figure 1). The initiative saw a new bridge considered following the failure of the previous structure within a year of its construction. The failure was attributed to the effect of floods. It is in the same vein that this study recognizes the importance of estimating the design peak discharges associated with the different return periods. The study, therefore attempts to estimate discharge with a 50 -year return period along the Nkana River at the project site (Figure 1).

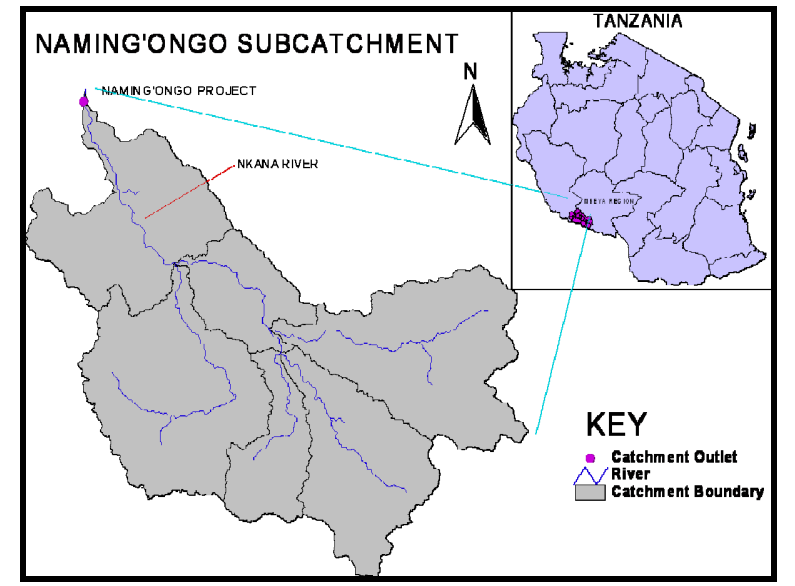

Figure 1. Location of the Naming'ongo project in Mbeya, Tanzania. 
Several studies have been done to estimate the frequency of discharges as well as rainfall. Kagoda and Ndiritu (2008) studied the frequency of rainfall using the Bayesian Inference approach. For longer return periods, the rainfall magnitudes of Bayesian estimates were found to be greater than those obtained using the regional storm index methodology [2]. In another study, pattern recognition fuzzy model employing cause-and effect as well as statistical analysis was used to estimate the peak discharge at Yichang Station along the Yangtze River [3] and the results indicated that the approach is effective. With respect to ungauged catchments, parameters that satisfactorily represent the Ruaha Catchment response were obtained by collating the physical catchment properties (topography, geology, climate and land) and calibrated parameters from gauged catchments using the Geographical Information System [4]. However, the uncertainty associated with the model parameter estimates depends on the importance of the collated physical catchment properties and may be corrected by the use of weighted regression approach [5].

In this study, the Australian Water Balance Model was calibrated and the identified model parameters values were further used to identify physical catchment attributes that could be used to undertake discharge frequency analysis in ungauged catchments.

\section{Description of the Study Area}

The delineated Naming'ongo sub-catchment as shown in Figure 1 is located in a semi-arid region in the southern highlands of Tanzania in Mbozi District and covers an area of $895 \mathrm{~km}^{2}$. Most of the rainfall is received on the eastern part of the catchment and decreases towards the western side. The sub-catchment is drained by River Nkana which is a tributary of River Momba and flows into Lake Rukwa. The outlet of the catchment is where the headworks for the irrigation scheme are located. The irrigation water diverted through the headworks flows through the lead canal to the rice farming area. In addition to the silt water that flows in River Nkana that have been noted of further increasing the soil nutrients suitable farming, the farms are characterised by alluvial soil that have been noticed of being suitable for farming. The rice farming activity is normally carried out during the month of December through April when the flows in the river are high.

\section{Data and Method}

\subsection{Australian Water Balance Model}

The Australian water balance model (AWBM) was developed to relate the daily rainfall and daily evapotranspiration to runoff $[6,7]$. The model employs 5 concep- tual stores, 3 conceptual surface stores to simulate partial area that generate excess rainfall and the other 2 conceptual stores are the surface store and base flow store.. Each surface store's water balance is calculated independently (Equation (1)) and the excess contributes to the surface runoff store and base flows. At every time step rainfall is added to each store and evapotranspiration is subtracted; this ensures that all the conceptual stores' water is accounted for in each time step.

$$
S_{k, t+1}=S_{k, t}+R_{t}-E_{t}
$$

where $S$ is the storage of store $k$ ( 1 to 3 ) at time step $t, R$ is the rainfall and $E$ is the evapotranspiration. When the amount of rainfall received is higher than the storage capacity $S_{k, t}+1$, the excess rainfall is generated. When runoff occurs part of it contributes to base flow. Among suitable features of the AWBM is its ability to simulate delayed surface runoff for medium and large catchments, a fact that makes it a suitable model for the delineated Naming'ongo sub-catchment and other similar catchment. The commonly used optimization strategy [8-10], the shuffled complex evolution [11] was employed in this study to undertake the calibration of the AWBM model parameters. Following the catchment processes being complex and nonlinear, the root mean square error was used as an objective function since it is nonlinear [12]. The Nash-Sutcliffe and the correlation coefficient were used as the model performance measures. The values range from zero to one and a perfect match between simulated and observed is one [13].

\subsection{Data Used}

In addition to the $30 \mathrm{~m} \mathrm{DEM}$, the other data used includes 10 years observed data of rainfall, potential evaporation, and stream flow data. The data was obtained from Mbozi Meteorological Station and Rufiji Basin Office.

\section{Methodology}

The methodology involved:

a) Delineation of the catchment and identification of the river network: A $30 \mathrm{~m}$ digital elevation model (DEM) using the ARCSWAT an extension of ArcGIS was used in determining the sub-catchment boundary, area as well as the river network based on the DEM.

b) Identification of suitable parameters of AWBM: The AWBM was calibrated using the data for Mbarali catchment. The catchment characteristics of Mbarali have been observed of having some similarities. Therefore, the obtained parameters were considered adequate for the Naming'ongo Project.

c) Simulation of the flows: The model was set for Naming'ongo Sub-Catchment and the flows in River 
Nkana were simulated.

d) Identification of the annual peak flows: The annual peak flows were identified and thereafter the series were ranked and the probabilities attached. The values were extrapolated on a semi-log scale.

\section{Results and Discussion}

\subsection{Calibration of the Model}

The upper and lower limits of parameter search range used were in line with the AWBM model developers' recommendations and a total of 8 parameters were calibrated. The values obtained are within the range as shown in Table 1. Although there is no suitable explanation with regard to the $3^{\text {rd }}$ surface store, the constrained portion of the catchment area was found to have a capacity value for the third surface store of zero. The model performance based Nash-Sutcliff obtained during calibration was 0.48 and the corresponding correlation coefficient was 0.538 for the Mbarali Sub-catchment. The lower values obtained can be attributed to the location of the gauging stations on the lower side of the catchment. The end of the catchment normally receives less rainfall than the higher altitudes and therefore cannot be considered as one of the driver stations for the catchment [9]. Figure 2 shows the observed and calibrated flows. The simulated flow time series plot suggests that satisfactorily trend has been obtained; however, the lower flows values have been satisfactorily simulated. This can be attributed to the lower observed rainfall values that are not representative of the catchment areal estimates and higher evaporation rate. This calls for the need for establishing gauging station on the higher altitudes of the catchment that normally receives higher rainfall and less evaporation values.

\subsection{Simulation Results for River Nkana}

The simulation results suggest that the annual peak values range from $146 \mathrm{~m}^{3} / \mathrm{s}$ to $395 \mathrm{~m}^{3} / \mathrm{s}$ (Figure 3). For 50

Table 1. Calibrated parameters.

\begin{tabular}{lcccc}
\hline & Parameter & Value & Lower limit & Upper limit \\
\hline 1 & $\mathrm{~A} 1$ & 0.9998 & 0 & 1.0 \\
2 & $\mathrm{~A} 2$ & 0.0002 & 0 & 1.0 \\
3 & $\mathrm{~A} 3=1-\mathrm{A} 1-\mathrm{A} 2$ & 0 & & \\
4 & $\mathrm{BFI}$ & 0.07865 & 0 & 1.0 \\
5 & $\mathrm{C} 1$ & 1.444 & 0 & 50.0 \\
6 & $\mathrm{C} 2$ & 127.7031 & 0 & 200.0 \\
7 & $\mathrm{C} 3$ & 194.7391 & 0 & 500.0 \\
8 & Kbase & 0.0137 & 0 & 1.0 \\
9 & KSurf & 0.6382 & 0 & 1.0 \\
\hline
\end{tabular}

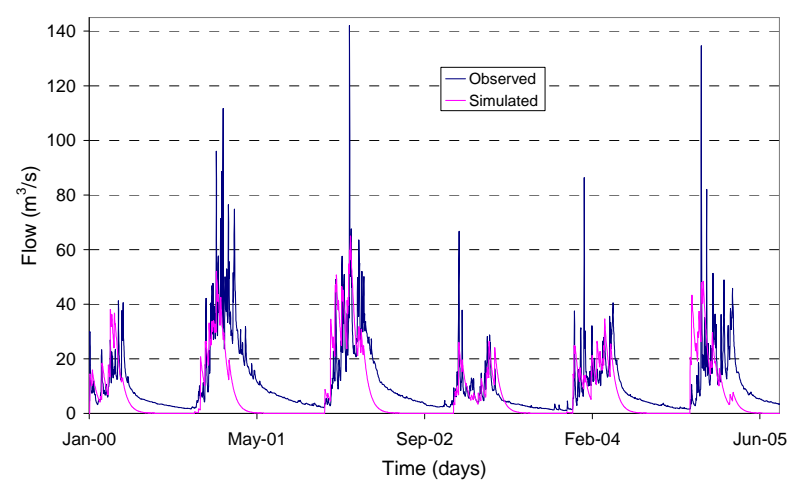

Figure 2. Observed and simulated flows for the Mbarali sub-catchment during calibration.

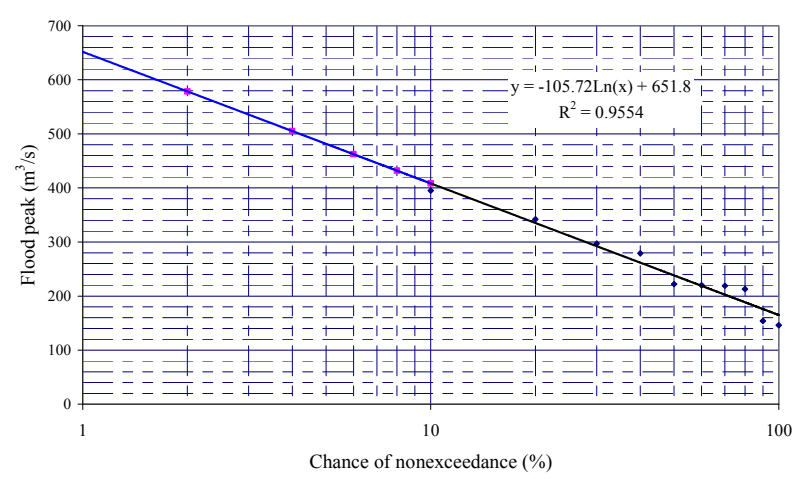

Figure 3. Probability of nonexceedance for the annual peak values along River Nkana.

years return period the probability of nonexceedance is $2 \%$ and corresponds to $578 \mathrm{~m}^{3} / \mathrm{s}$ (Figure 3) and is close to what was obtained from Mbeya Zone Irrigation Unit.

\subsection{Likely Sources of Uncertainties}

In estimating peak discharge in an ungauged catchment, several sources of uncertainties exist and in a situation where the uncertainties are not accounted for, the obtained values are considered to be approximate values [14]. The uncertainties can be classified into three categories, the knowledge uncertainty, natural variability and decision uncertainty [15]. In the Naming'ongo Subcatchment, several factors that are likely to affect the model results exist. These include the nonexistence of streamflow gauging stations, the spatial and temporal variability of the rainfall, the spatial and temporal variability of the hydrological process and human impact. In addition, the various assumptions made during the identification of the two different catchments to be considered of having similar characteristics, may require an explicit analysis which not the subject of this study. Future activities need to account for land and environmental conservation when undertaking some human activities such as deforestation and the cultivation practices. In addition to this, the current and future development of 
many hydraulic structures within the catchment and beyond should incorporate stream flow measuring facilities.

\section{Conclusion and Recommendation}

Following the response by the government of Tanzania in addressing food security and poverty alleviation in Naming'ongo area in Mbozi District, is by developing Naming'ongo irrigation scheme as well as construction of bridges across River Nkana that connects the farms and other parts of the district to facilitate a reliable transportation of the farm produce. The Australian Water Balance Model that was calibrated by using 10 years hydrological and meteorological data from a nearby sub-catchment of Mbarali, and the calibrated model was then applied to simulate the flows in River Nkana. The study approximated the average peak flows in River Nkana for a return period of 50 years to be just above $560 \mathrm{~m}^{3} / \mathrm{s}$. This discharge level was considered to be adequate for the proposed structure. The study recommends that the human activities including deforestation and cultivation should incorporate soil and environmental conservation. While it is necessary to establish a monitoring system within the catchment, the designs of future intake structures should incorporate stream flow measuring facilities.

\section{Acknowledgements}

The authors acknowledge the support received from the Mbeya University of Science and Technology. Comments received are also acknowledged.

\section{REFERENCES}

[1] F. P. Maganga, et al., "Situation and Stakeholder Analysis with a Focus on Selected Catchment Area of the Great Ruaha Catahment," World Wide Funds for Nature (WWF), 2011.

[2] P. Kagoda and J. Ndiritu, "Analysis of the Effect of Parameter Uncertainty in Rainfall Frequency Estimation," Water Resource Management (AfricaWRM 2008), Gaborone, 8-10 September 2008.

[3] G. H. Hu, S. Q. Sun and X. Yin, "Long Term Forecast of Annual Maximum Peak Discharge at Yangtze Three Gorges Based on Fuzzy Method," Proceedings of International Conference on Intelligent Computation Technology and Automation, Changsha, 20-22 October 2008, pp. 899-903.

[4] S. Mwakalila, "Estimation of Stream Flows of Ungauged
Catchments for River Basin Management," Physics and Chemistry of the Earth, Parts A/B/C, Vol. 28, No. 20-27, 2003, pp. 935-942.

[5] T. Wagener and H. S. Wheater, "Parameter Estimation and Regionalization for Continuous Rainfall-Runoff Models Including Uncertainty," Journal of Hydrology, Vol. 320, No. 1-2, 2006, pp. 132-154. doi:10.1016/j.jhydrol.2005.07.015

[6] W. Boughton, "The Australian Water Balance Model," Environmental Modelling \& Software, Vol. 19, No. 10, 2004, pp. 943-956. doi:10.1016/j.envsoft.2003.10.007

[7] W. Boughton and F. Chiew, "Estimating Runoff in Ungauged Catchments from Rainfall, PET and the AWBM Model," Environmental Modelling \& Software, Vol. 22, No. 4, 2007, pp. 476-487.

doi:10.1016/j.envsoft.2006.01.009

[8] J. Ndiritu, "Automatic Calibration of the Pitman Model Using," The Shuffled Complex Evolution (SCE-UA) Method Water Research Commission, 2009, WRC Report No. KV 229/09.

[9] P. A. Kagoda, et al., "Application of Radial Basis Function Neural Networks to Short-Term Streamflow Forecasting," Physics and Chemistry of the Earth, Parts $A / B / C$, Vol. 35, No. 13-14, 2010, pp. 571-581. doi:10.1016/j.pce.2010.07.021

[10] Z. Katambara and J. G. Ndiritu, "A Hybrid ConceptualFuzzy Inference Streamflow Modelling for the Letaba River System in South Africa," Physics and Chemistry of the Earth, Parts A/B/C, Vol. 35, No. 13-14, 2010, pp. 582595. doi:10.1016/j.pce.2010.07.032

[11] Q. Y. Duan, S. Sorooshian and V. Gupta, "Effective and Efficient Global Optimization for Conceptual RainfallRunoff Models," Water Resources Research, Vol. 28, No. 4, 1992, pp. 1015-1031. doi:10.1029/91WR02985

[12] Z. Katambara and J. Ndiritu, "A Fuzzy Inference System for Modelling Streamflow: Case of Letaba River, South Africa," Physics and Chemistry of the Earth, Parts $A / B / C$, Vol. 34, No. 10-12, 2009, pp. 688-700. doi:10.1016/j.pce.2009.06.001

[13] D. N. Moriasi, et al., "Model Evaluation Guidelines for Systematic Quantification of Accuracy in Watershed Simulations," Transactions of the ASABE, Vol. 50, No. 3, 2007, pp. 885-900.

[14] A. Bardossy, A. Bronstert and B. Merz, "1-, 2- and 3Dimensional Modeling of Water Movement in the Unsaturated Soil Matrix Using a Fuzzy Approach," Advances in Water Resources, Vol. 18, No. 4, 1995, pp. 237-251. doi:10.1016/0309-1708(95)00009-8

[15] D. P. Loucks, et al., "Water Resources Systems Planning and Management: An Introduction to Methods, Models and Applications," UNESCO, Paris, 2005. 